\title{
LA POBLACIÓN DE CUBA. SU EVOLUCIÓN Y CARACTERÍSTICAS ACTUALES
}

POR

\author{
SONIA MONTIEL RODRÍGUEZ
}

La población cubana, que en el año 1993 llegó a los 10.940 .000 habitantes (CEE, 1994), presenta en su evolución y en la actualidad rasgos muy interesantes que se reflejarán en estas líneas; primero abordaremos la dinámica demográfica natural, para continuar con la composición de la población cubana y complementar estos análisis con la distribución de la población y las migraciones tanto internas como externas. Por último, haremos una breve reflexión sobre la población cubana a las puertas del próximo siglo. Estamos conscientes que este tema no está totalmente agotado, ya que sólo se han caracterizado los aspectos que hemos considerado más importantes desde un punto de vista geográfico.

\section{La dinámica demográfica natural}

La evolución de la población cubana, desde el momento de su colonización hasta la década de los años treinta de este siglo, presenta la marca de grandes corrientes migratorias que influyeron decisivamente en el comportamiento de las variables demográficas. Posteriormente, el movimiento migratorio ha sido menos importante y el peso de la dinámica demográfica ha estado en el crecimiento natural, que a finales del siglo xx muestra un decrecimiento notable. 
A continuación intentaremos caracterizar los aspectos más sobresalientes de la evolución de la natalidad, la mortalidad y el crecimiento natural, haciendo énfasis en la situación actual de la dinámica demográfica referida a su comportamiento natural; en otro epígrafe analizaremos las migraciones de la población.

La natalidad. Con la información que existe en Cuba (Farnós y Catasús, 1976) es imposible conocer la situación de la natalidad de los aborígenes cubanos; la información más antigua que se puede obtener es a partir de los inicios del siglo XIX en los censos, donde ya aparece reflejada la información sobre la tasa bruta de natalidad que se considera en 1860 de 41,30 por 1.000 , disminuyendo hasta 32,8 por 1.000 en 1899 (Departamento de la Guerra, 1899).

Desde principios del siglo xx hasta los años treinta, Cuba se vio afectada por una gran inmigración vinculada al crecimiento de la industria azucarera en este período. En 1907, la tasa bruta de natalidad fue de 47,6 por 1.000 y en 1919 es de 39,6 por 1.000 , estos valores de la natalidad, sin lugar a dudas, están estrechamente relacionados con el crecimiento económido de este período (conocido como «Danza de los Millones», por los precios elevados que alcanzó el azúcar al concluir la Primera Guerra Mundial).

Después de 1919 comenzó a disminuir la natalidad hasta principios de la década de los años sesenta. En este período de crisis, llamado «modelo colonial cubano», se estanca la industria azucarera, se cortan las oleadas de inmigrantes y se agravan los problemas sociales y económicos del país, principalmente en la década de los años cincuenta, con la tiranía de Fulgencio Batista (1952-1958). La evolución de la natalidad, según la tasa bruta, se ha reflejado en la Figura 1.

A partir de 1959 (CEE, 1994) se puede observar el incremento de la tasa bruta de natalidad, en lo que influyeron importantes hechos económicos, políticos y sociales vinculados al triunfo de la Revolución, como son la estabilidad social, la seguridad económica y un importante avance en la atención médica. También influyó en estos años de la década de los sesenta, el desarrollo educacional, que después invierte su influencia y actúa en el descenso acelerado de la natalidad. En el año 1964 se considera que ocurrió un «baby boom» al alcanzar la tasa bruta de natalidad su valor máximo de 36,3 por 1.000 . 


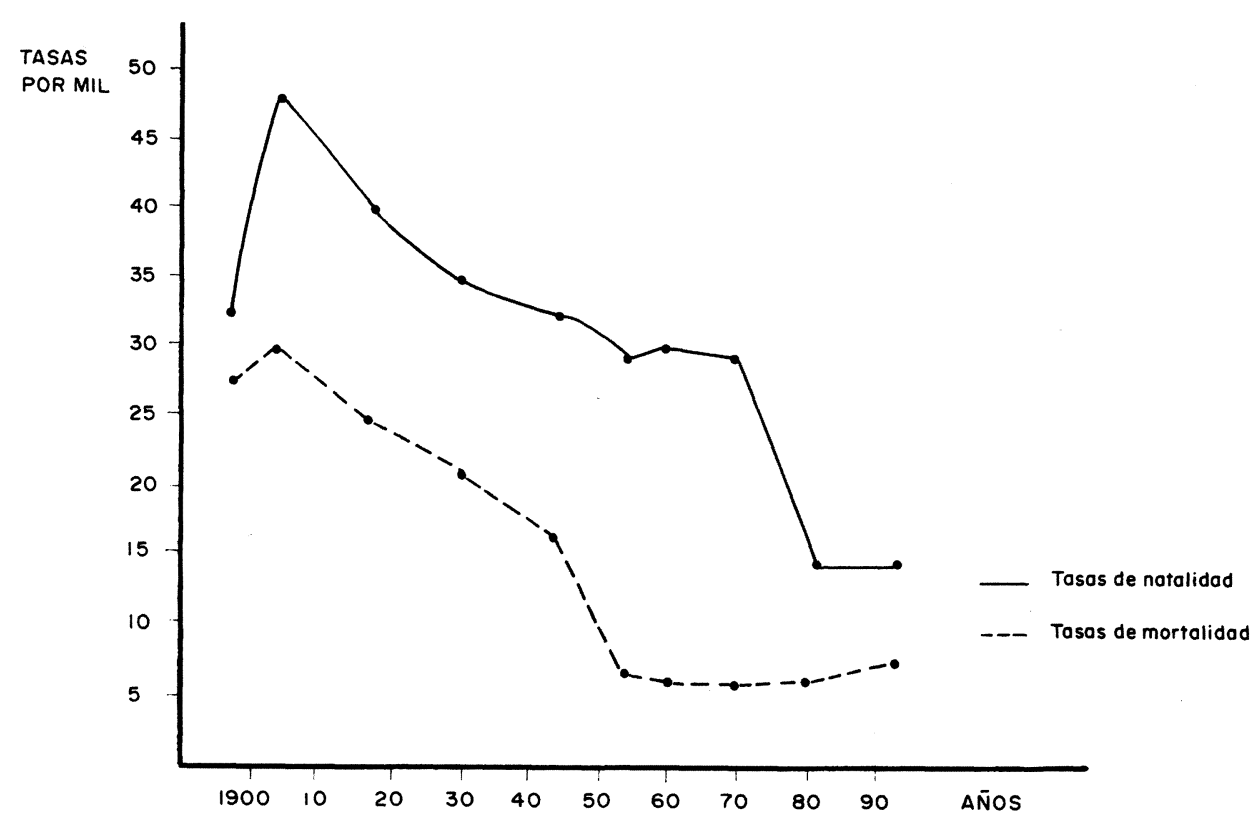

Fuente: Elaborado por la autora a partir de la información del Anuario Demográfico de Cuba de 1993, CEE.

Figura 1.-Evaluación de las tasas de natalidad y mortalidad, 1899-1993.

Después de las décadas de los sesenta y setenta, la natalidad no ha dejado de decrecer, en el Censo de 1970 alcanza un valor de 27,7 por $1.000 \mathrm{y}$ en el de 1981 desciende a 14,1 por 1.000 , el mínimo valor que vuelve a repetirse en 1994. Los valores tan bajos que presenta la natalidad cubana son consecuencia de dos factores fundamentales, en primer lugar, del nivel educacional de la población en general y de las mujeres en particular, así como su incorporación a la vida social y a la actividad laboral y en segundo lugar, al desarrollo de un importante plan de atención médica vinculado a la salud reproductiva y materno infantil. También en la década de los años noventa ejerce su influencia la situación de crisis económica que presenta el país, que, sin lugar a dudas, afecta el comportamiento de la natalidad.

Si se compara la distribución geográfica de la tasa bruta de natalidad por provincias, se observan algunas diferencias territoriales de interés. En las provincias más occidentales, la tasa bruta de natalidad

$$
-247-
$$


tiene los menores valores, 12,2 por 1.000 en la capital, La Habana, que es el valor más bajo de todo el país; en las provincias centrales presenta valores intermedios, que son de 12,6 a 13,8 por 1.000 , y en las provincias orientales, las menos desarrolladas económica y socialmente, los valores son relativamente más elevados de 14,1 a 18,5 por 1.000 (véase Figura 2).

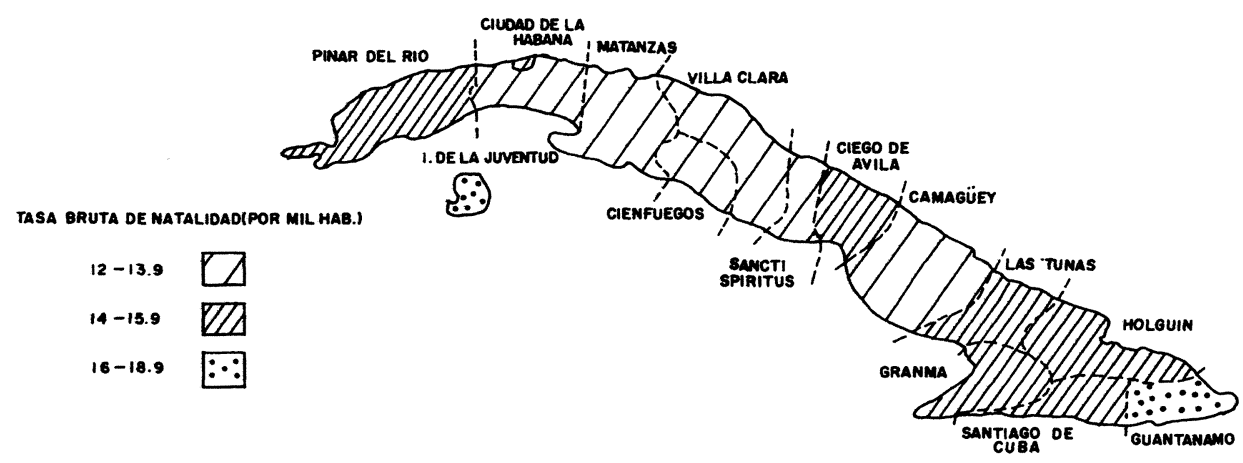

FUENTE: Elaborado por la autora a partir de la información del Anuario Geográfico de Cuba de 1993 CEE.

Figura 2.-Distribución geográfica de la natalidad por provincias, 1993.

Otros indicadores de la natalidad cubana en los últimos años también reflejan de forma acusada el descenso de la misma. Por ejemplo, la tasa general de fecundidad en el año 1992 fue de 51.5 por 1.000 , la tasa global de fecundidad de 1,52 hijos por mujer y la tasa bruta de reproducción de 0,74 hijas por mujer; todos estos valores (CEE, 1994) nos permiten afirmar que la natalidad cubana medida por los indicadores de la fecundidad es una de las más bajas del Mundo.

La mortalidad. Al igual que ocurre con la natalidad, el análisis de la mortalidad no resulta fácil en la época colonial por los problemas de escasez de información. En el siglo XIX aparecen los primeros valores de la tasa bruta de mortalidad (Farnós y Catasús, 1976), que oscila alrededor del 40 por 1.000; en todo este período hubo grandes epidemias y guerras, lo que justifica los altos valores de la mortali-

$$
-248-
$$


dad en este siglo, que según el Censo de 1899, alcanzó en el año 1898 el valor de 91 por 1.000 , el valor máximo de la mortalidad en Cuba en toda su evolución.

En el inicio de este siglo comienzan importantes avances en la salud pública; el hecho que más se destacó fue el descubrimiento del doctor Carlos J. Finlay del agente transmisor de la fiebre amarilla, lo que permitió tomar algunas medidas para combatir dicha epidemia. Además se registraron avances en el abastecimiento de agua potable en las ciudades y se comienzan los trabajos de alcantarillado en las mismas. La tasa bruta de mortalidad en el año 1899 fue de 26,3 por 1.000 , y aumentó ligeramente en 1907 a 29,7 por 1.000 , para empezar un descenso gradual hasta la actualidad. Es importante destacar la rápida reducción después de la Segunda Guerra Mundial.

La evolución de la mortalidad general, según la tasa bruta, se puede apreciar en la figura 1. Después del triunfo de la Revolución, en el primer censo realizado, el de 1970 , se refleja un valor de la tasa bruta de 6,3 por 1.000; en el de 1981 se observa uno de los valores más bajos 5,9 por 1.000, y en las estimaciones realizadas para el año 1993 presenta un valor de 7,2 por 1.000 , lo que demuestra que la mortalidad cubana ha comenzado a aumentar por el creciente envejecimiento de la población cubana, a lo que se hará referencia más adelante.

La distribución territorial de la mortalidad general por provincias (véase figura 3) presenta pequeñas diferencias, encontrándose los va-

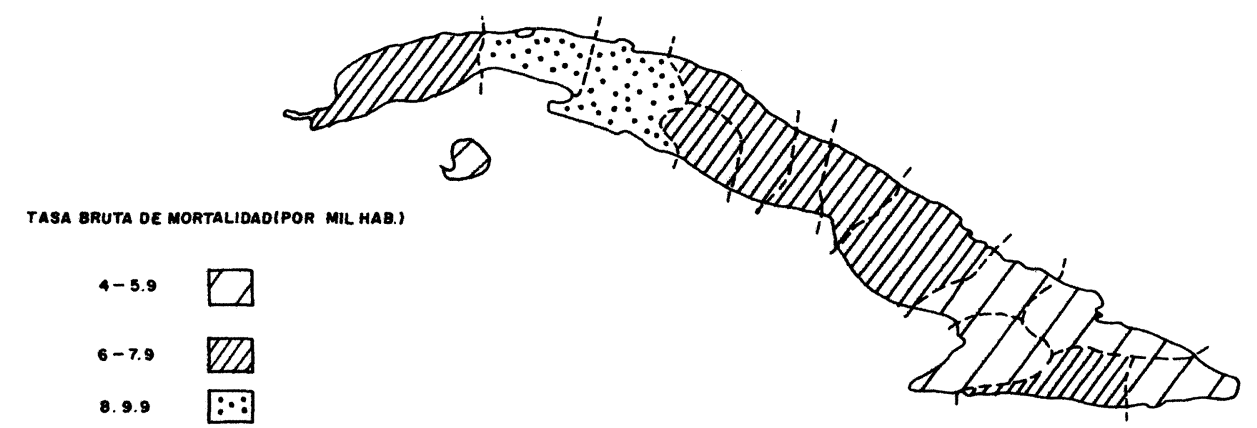

Fuente: Elaborado por la autora a partir de la información del Anuario Geográfico de Cuba de 1993 CEE.

FIGURA 3.-Distribución geográfica de la mortalidad general por provincias, 1993.

$$
-249-
$$


lores más altos en las provincias occidentales y centrales y los valores menores en las provincias orientales.

La evolución de la esperanza de vida desde principios de siglo ha tenido un gran aumento, específicamente en los últimos veinte años. Según Farnós y Catasús, la esperanza de vida fue de 33 años a principio de siglo, llegando en los años treinta a 41,5 años. La información más reciente de que disponemos es para el año 1986-87 (CEE, 1994), donde para ambos sexos fue de 74,46 años, siendo de 72,74 años para los varones y de 76,34 años para las mujeres, lo que sitúa a Cuba entre los países donde la población tiene una mayor esperanza de vida al nacer.

En relación a la mortalidad infantil, si se analiza su comportamiento, como lo hemos realizado para la mortalidad general, se aprecian valores elevadísimos en los primeros años de este siglo; en 1899 (Toirac y Velázquez) fue de 224,7 por 1.000 , en 1907 desciende a 213 por 1.000 , para continuar su descenso a través del siglo y llegar en 1970 a 378,7 por 1.000 , en 1981 a 18,5 por 1.000 y en 1993 a 9,4 por 1.000 , valores muy bajos, si se comparan con otros países del Mundo, lo que está estrechamente vinculado a los diferentes programas de Salud Pública relacionados a la atención a las madres y a los recién nacidos.

La mortalidad infantil en su distribución geográfica presenta variaciones, aunque en todas las provincias se presenten valores muy bajos, que oscilan entre 6,6 y 11,6 por 1.000 (véase Figura 4).

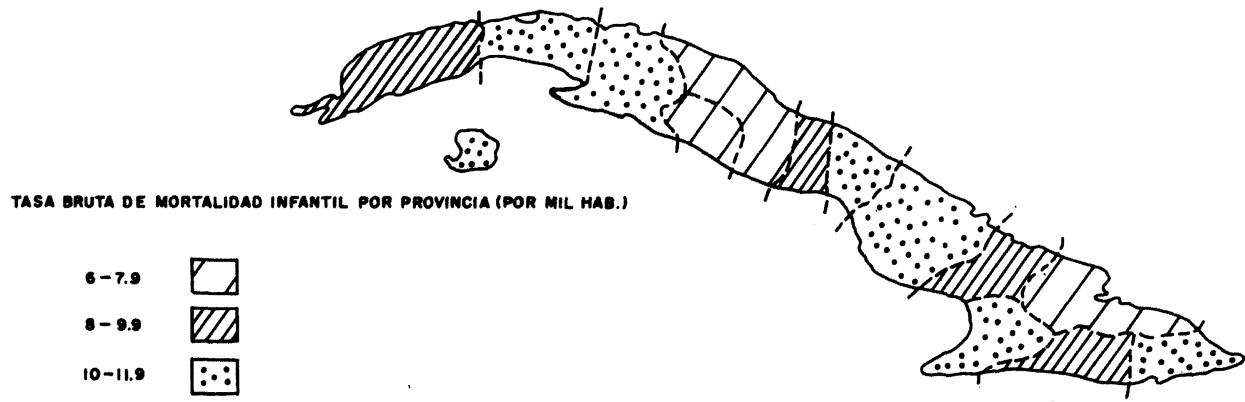

FuENTE: Elaborado por la autora a partir de la información del Anuario Geográfico de Cuba de 1993 CEE.

Figura 4.-Distribución geográfica de la mortalidad infantil por provincias, 1993.

$$
-250-
$$


El crecimiento natural. La población aborigen se ha estimado entre 80.000 y 100.000 personas al inicio de la conquista (Pérez de la Riva, 1973); debido a diferentes causas, como la matanza indígena, las nuevas enfermedades y el hambre, prácticamente desapareció, quedando unas 4.000 o 5.000 personas. Además, el incremento de la población entodo este período, hasta finales del siglo xvIII fue muy lento.

Muchos autores (Mazorra y Castellón, 1976) analizan la evolución del crecimiento de la población según los censos de población y establecen tres estapas importantes: el Período Colonial, la República Mediatizada (1899 a 1958) y después del triunfo de la Revolución en 1958; siguiendo estas etapas se puede apreciar que existen diferencias en el comportamiento del crecimiento poblacional (véase Cuadro I).

\section{Cuadro I}

CUBA. POBLACIÓN Y TASA DE CRECIMIENTO ANUAL (1774-1993)

\begin{tabular}{|c|c|c|}
\hline Año & $\begin{array}{l}\text { Población } \\
\text { en miles }\end{array}$ & $\begin{array}{c}\text { Tasa de } \\
\text { crecimiento (\%) }\end{array}$ \\
\hline 1774 & 172,6 & - \\
\hline $1792 \ldots .$. & 272,3 & 2,53 \\
\hline $1817 \ldots \ldots \ldots \ldots \ldots \ldots . . . . .$. & 553,0 & 2,83 \\
\hline 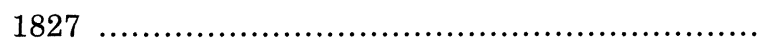 & 704,5 & 2,42 \\
\hline …......................... & $1.007,6$ & 2,56 \\
\hline 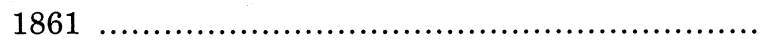 & $1.396,5$ & 1,63 \\
\hline ............................... & $1.521,7$ & 0,54 \\
\hline n........................... & $1.631,7$ & 0,70 \\
\hline $1899 \ldots$. & $1.572,8$ & $-0,31$ \\
\hline $1907 \ldots \ldots$. & $2.049,0$ & 3,34 \\
\hline (n........................... & $2.889,0$ & 2,86 \\
\hline 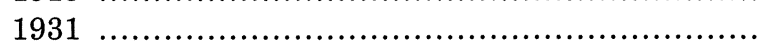 & $2.962,3$ & 2,63 \\
\hline 1943 ................................................ & $4.778,6$ & 1,58 \\
\hline 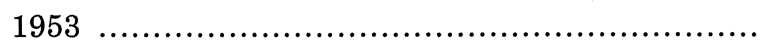 & $5.829,0$ & 2,09 \\
\hline 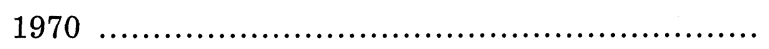 & $8.495,4$ & 1,51 \\
\hline $1981 \ldots \ldots \ldots \ldots \ldots \ldots \ldots$ & $9.753,2$ & 0,61 \\
\hline 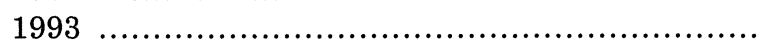 & $10.940,6$ & 0,66 \\
\hline
\end{tabular}

FuENTE: Mazorra, R. y Hernández, R. El crecimiento de la población, en La población de Cuba, pág. 7-20 y Anuario Demográfico de Cuba, 1993. 
Desde 1774 hasta 1841, el crecimiento poblacional fue bastante acelerado, las tasas de crecimiento medio anual así lo demuestran; el mismo fue resultado de la expansión de la economía azucarera y del incremento de la población esclava que se estimó en 1840 alrededor de 436.000 personas, prácticamente la mitad de la población de Cuba en esa fecha. A partir de 1845, cuando se suspende, al menos aparentemente, la trata de esclavos, el crecimiento de la población comenzó a disminuir. Después de la segunda mitad del siglo XIX comienzan las Guerras de Independencia, que inciden decisivamente en los valores pequeños del crecimiento poblacional, llegando al fin del siglo con un crecimiento negativo de la población cubana.

En la República Mediatizada (Luzón, 1987), el crecimiento natural se recuperó fundamentalmente debido al aumento de la natalidad y a la disminución de la mortalidad general. En su distribución geográfica, desde 1899 a 1958, se aprecian fuertes diferencias en su comportamiento vinculado a la expansión del cultivo de la caña de azúcar y a la construcción de nuevas líneas del ferrocarril y en la década de los treinta a la construcción de la Carretera Central.

En las tres primeras décadas de este siglo, el crecimiento poblacional estuvo determinado por las diferentes oleadas de inmigración.

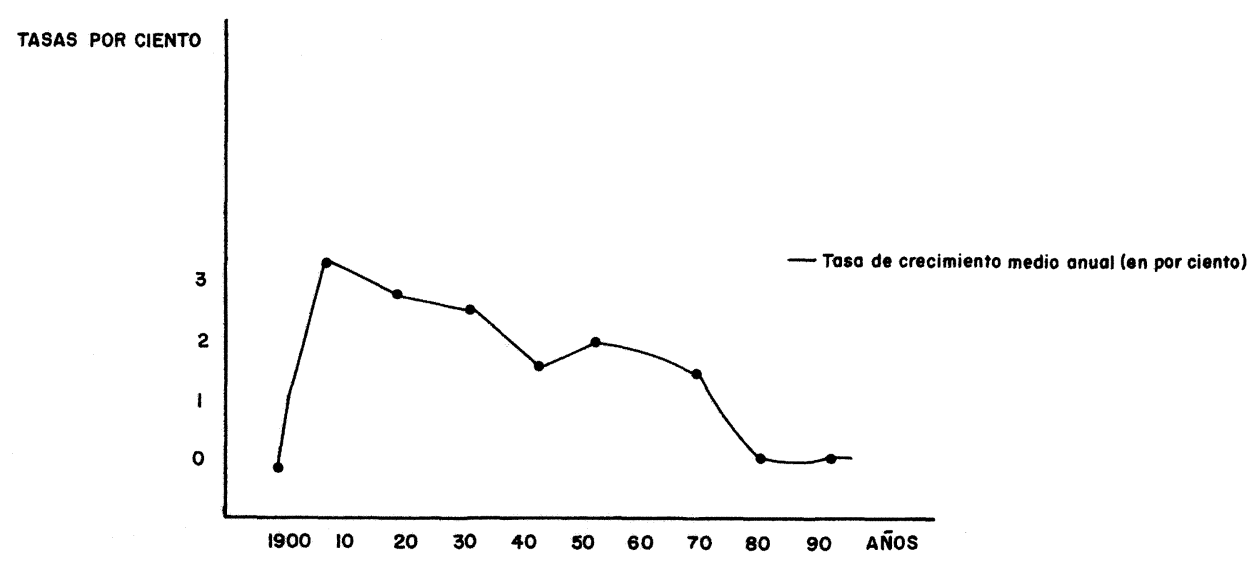

FuENTE: Elaborado por la autora a partir de la información del Anuario Demográfico de Cuba, 1993 CEE.

Figura 5.-Evolución de las tasas de crecimiento, 1899-1993.

$$
-252-
$$


A partir de 1931, el crecimiento poblacional disminuye de forma acentuada y se basa en el crecimiento vegetativo (véase cuadro I). Las tasas de crecimiento más fuertes se pueden observar en las provincias de Oriente y Camagüey, las más orientales del país, desde 1899 hasta 1953 , donde alcanzaron valores de 3,8 y 4,9\%, respectivamente en el período intercensal $1899-1931$ y de 3,20 y $3,6 \%$, si se considera el período intercensal 1899-1953.

A partir de 1958 y hasta la década de los setenta, con las nuevas transformaciones sociales, económicas y políticas, como ya hemos señalado, se recupera la natalidad y disminuye la mortalidad general e infantil, el ritmo de crecimiento medio anual ha estado oscilando, en las décadas de los sesenta y setenta entre 2,5-1,5\%, para situarse en los años ochenta y noventa con valores inferiores al 1,0\%. Esta evolución que es poco normal, obedece en los primeros años al «baby boom», que ya hemos comentado, después del triunfo de la Revolución. A partir de 1981, la tasa de crecimiento media anual ha descendido drásticamente, lo que nos hace suponer que entraremos en el próximo siglo con valores muy bajos en el crecimiento poblacional (cuadro I).

\section{La composición de la población}

La población cubana se puede caracterizar en su estructura por sexo y edad como una población donde predomina el sexo masculino sobre el femenino, como resultado de la fuerte inmigración del siglo XIX y las tres primeras décadas del siglo xx, estas oleadas de inmigración eran de adultos jóvenes, por lo que también repercutieron fuertemente en la estructura por edades de la población cubana.

El índice de masculinidad refleja, desde principios del siglo, un desequilibrio acentuado producto de la influencia de la inmigración en diferentes períodos. En 1899, la relación de masculinidad fue de 1.070 varones por cada 1.000 mujeres, aumentando hasta los años treinta; después comienza su disminución hasta llegar a la década de los noventa con valores de 1.011 varones por cada 1.000 mujeres.

La estructura por edades se vio marcada desde la época colonial por la inmigración, ya que aumentó la población adulta joven entre 

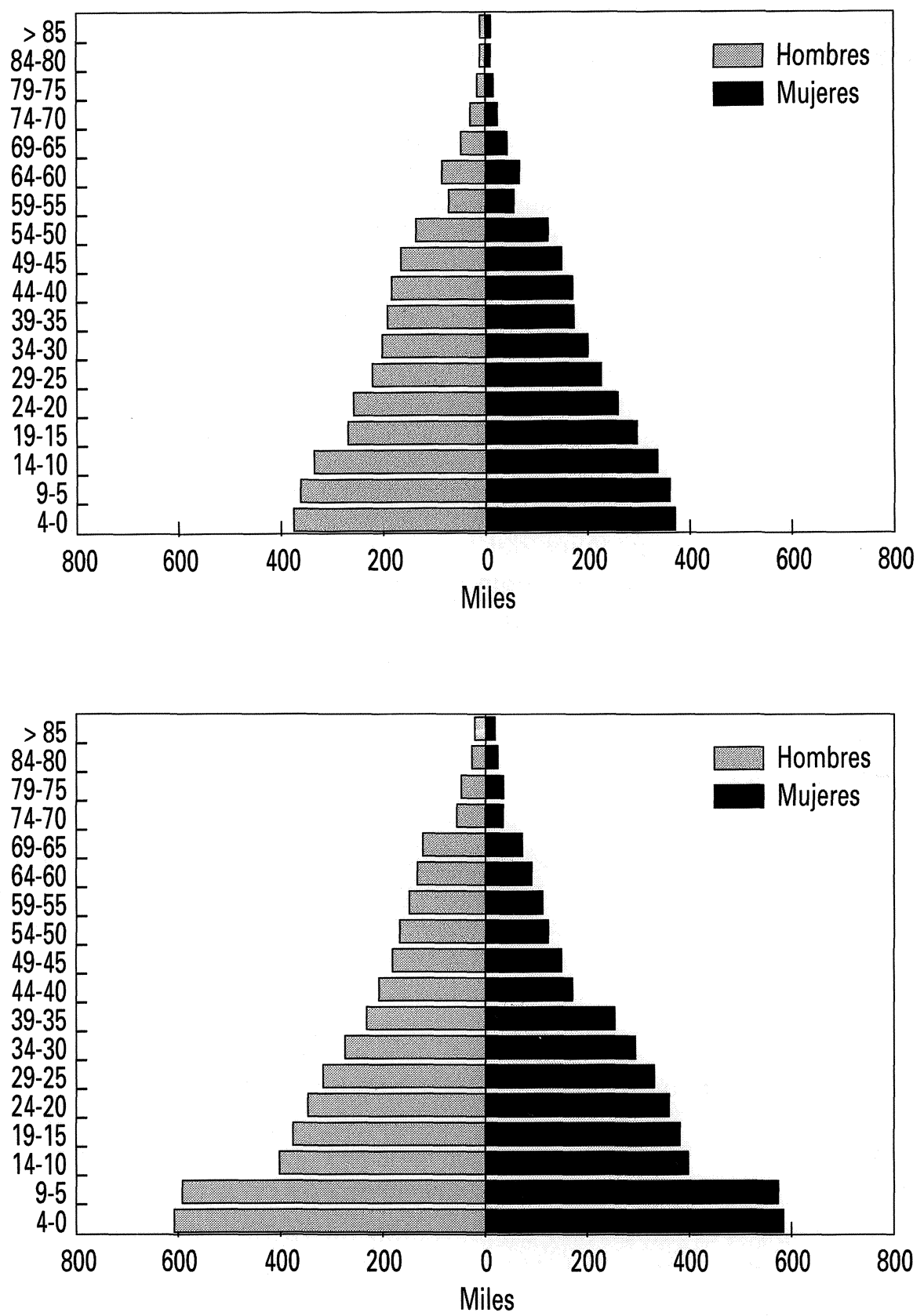

FIGURA 6a.-Estructura por sexo y edad en 1953 (arriba) y 1970 (abajo). 

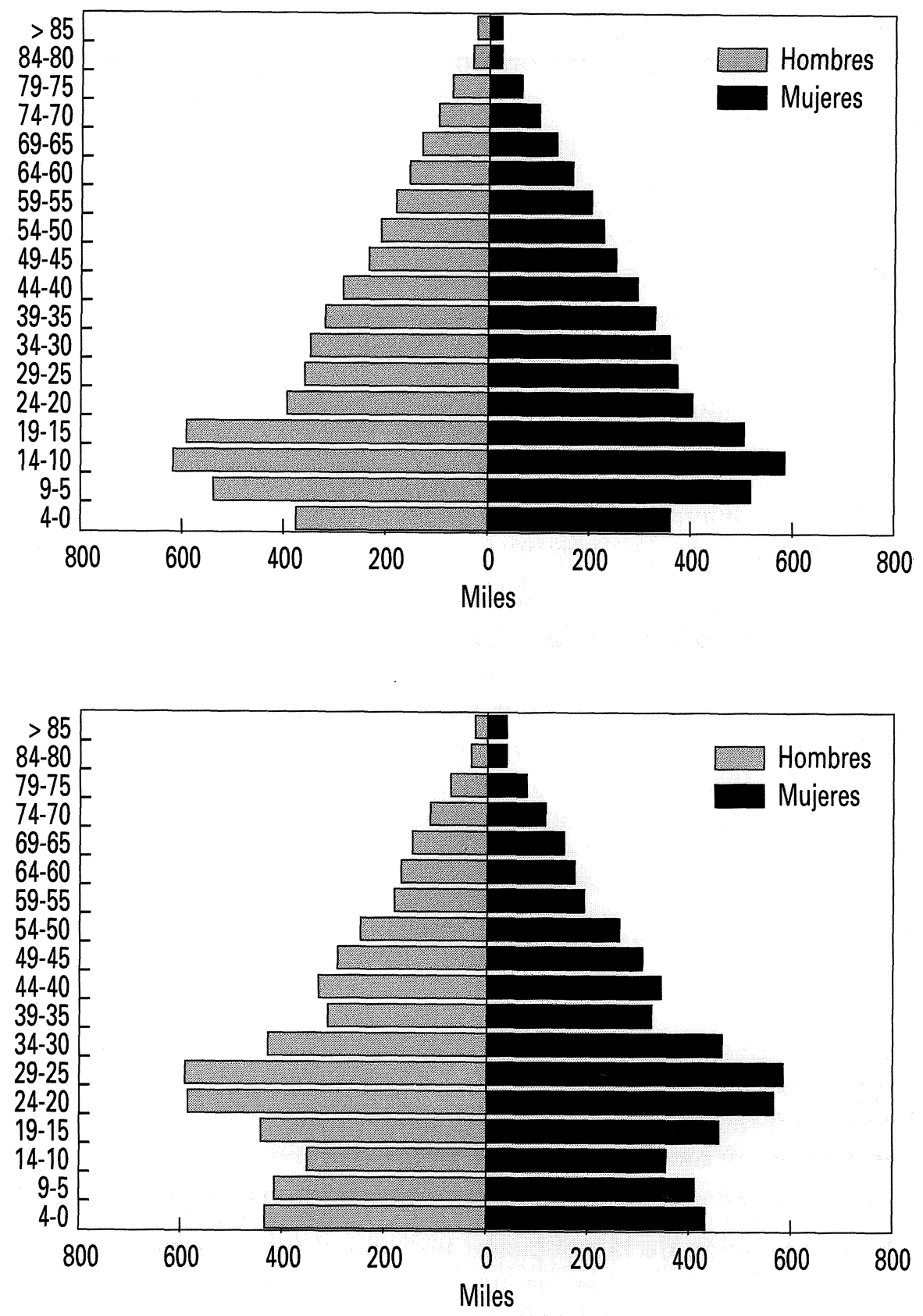

FIGURA 6b.-Estructura por sexo y edad en 1981 (arriba) y 1992 (abajo). 
los quince y los treinta y nueve años. También han actuado en la estructura por edades el comportamiento del crecimiento natural. A principios de este siglo se observa positivamente el efecto del mismo sobre la estructura por edades, esto se aprecia en la pirámide de 1953 (véase figura 6). La influencia posterior del fuerte crecimiento natural en la primera década del siglo se puede observar en esta misma figura. También han ejercido influencia en la estructura por edades de la población cubana las variaciones de la natalidad, principalmente las que ocurren a principios del siglo y en los años sesenta y el descenso de la mortalidad infantil a partir de los años cuarenta.

Hemos querido representar la evolución de la estructura por sexo y edades de la población cubana, según información de los tres últimos censos realizados en Cuba $(1953,1970,1981)$ y con la estimación de la población para el año 1993, en las pirámides que conforman la figura 6 .

Un aspecto muy importante que reviste la estructura por edades de la población cubana en la actualidad es su tendencia al envejecimiento, lo que es causado básicamente por la disminución de la natalidad y mortalidad de los últimos años. La proporción de personas de más de sesenta años en 1899 fue de 1,6\%, en 1943 de 5,6, en 1980 de 10,8 y en 1990 de $11,8 \%$, lo que da una idea del proceso de envejecimiento que está ocurriendo en la población cubana.

\section{La distribución de la población y las migraciones internas}

La población aborigen de Cuba se ha estimado entre 80.000 y 100.000 personas, asentadas en su mayoría en el este del país. Los primeros aborígenes fueron recolectores en una mayor proporción y habitaban en las costas y ciénagas, mientras la minoría, agricultores y ceramistas, se asentaron en las sabanas donde la densidad poblacional alcanzó sus valores máximos (Pérez de la Riva, 1973).

La distribución de la población en todo el período colonial estuvo centrada desde sus inicios, en un movimiento de las costas hacia el interior y en el oriente del país, lo que refleja en los primeros dos siglos de colonización española. Ya en el Censo de 1774 (el primero re- 
alizado en Cuba), en el departamento occidental se asentaba el $56 \%$ de la población del país y se observa un desarrollo del poblamiento en sentido este-oeste, lo que ocurre debido a algunos factores económicos que han estado incidiendo desde esta época, en la distribución espacial de la población; en primer lugar, el papel de la capital, La Habana, con una función de puerto de escala de la Flota Española y en segundo lugar, el cultivo de la caña de azúcar. Otros factores han jugado también un papel secundario como, por ejemplo, la existencia de recursos y condiciones naturales favorables, como suelos fértiles, la existencia de agua, etc. También el ferrocarril, que era la casi única forma de comunicación existente, incidió en la conformación del poblamiento cubano en el siglo XIX.

Ya en este siglo, el espacio geográfico cubano representaba una importante dualidad (Luzón, 1987). Las provincias occidentales mostraban una intensa ocupación (Pinar del Río, La Habana, Matanzas y la parte occidental de Las Villas) y las provincias orientales presentaban un importante vacío demográfico (el este de Las Villas, Camagüey y Oriente). Desde principios de este siglo, La Habana, la capital, concentraba la quinta parte de la población total del país y ha tenido un importante papel en los desequilibrios problacionales y territoriales desde esta fecha.

Toda la transformación económica y espacial del período republicano estuvo asociada al cultivo de la caña de azúcar. La ampliación de este cultivo requirió en las primeras décadas de este siglo gran fuerza de trabajo que fue cubierta por los inmigrantes procedentes, ya no de España, sino de Haití y Jamacia. El auge económico hizo que los españoles emigraran hacia las ciudades.

En la década de los años treinta, en plena crisis económica se construye la Carretera Central que influye decisivamente en la conformación del poblamiento, ya que la población se comenzó a asentar alrededor de un eje de $10 \mathrm{~km}$ de ancho y $1.220 \mathrm{~km}$ de extensión a lo largo de la misma, desde Pinar del Río hasta Guantánamo, concentrando a ambos lados de la carretera el $45 \%$ de la población cubana.

En todo el período colonial y hasta los años cincuenta del presente siglo, la densidad de población cubana ha sido la más baja de todo el poblamiento antillano. En 1899, la densidad total de Cuba fue del 17,7 
habitantes por $\mathrm{km}^{2}$; en 1931 fue de 34,5 habitantes por $\mathrm{km}^{2}$ y en 1953 fue de 50,9 habitantes por $\mathrm{km}^{2}$. Después del triunfo de la Revolución en 1959, se evidencian importantes cambios en la distribución de la población, si se tiene como referencia la información del Censo de 1970 , se observa que la densidad de población alcanza los 77,1 habitantes por $\mathrm{km}^{2}$, y en 1981 la densidad fue de 87 habitantes por $\mathrm{km}^{2}$ y en 1992 asciende a 98 . Si analizamos los valores de la densidad poblacional para las distintas provincias se observan grandes intereses que aparecen reflejadas en la Figura 7.

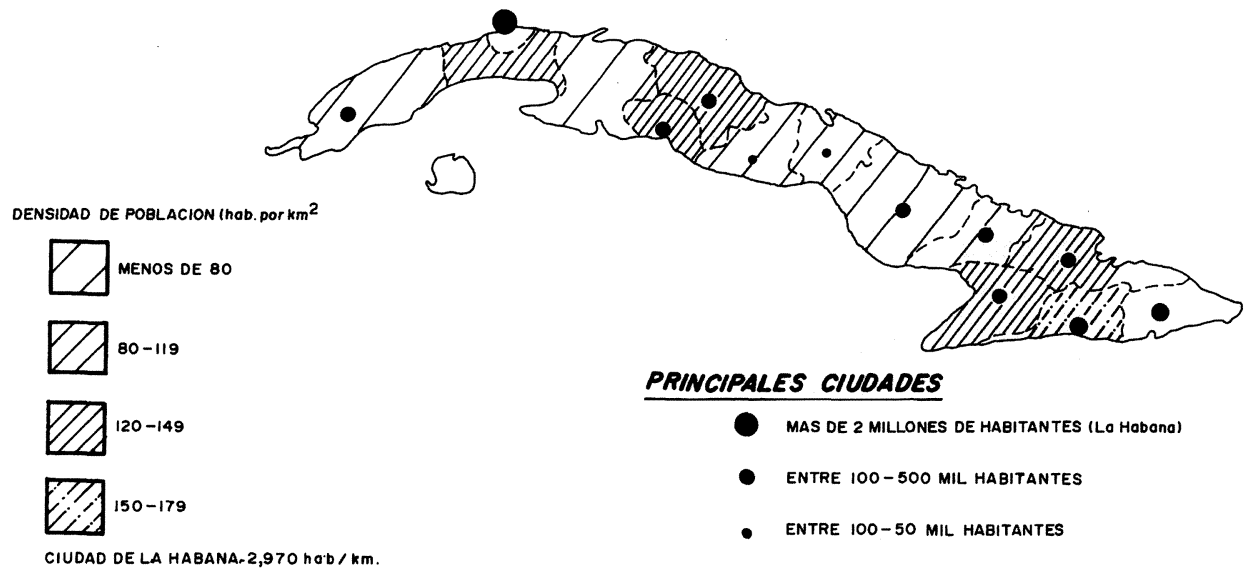

FuENTE: Elaborada por la autora a partir del Anuario Demográfico de Cuba, 1993.

Figura 7.-Densidad de población y principales ciudades en Cuba, 1993.

En estos últimos treinta años, la población cubana se ha urbanizado y concentrado fuertemente lo que ha provocado importantes cambios en el poblamiento del país. El crecimiento de la población urbana fue el mayor en el período intercensal 1970-1981; en el mismo, la población urbana pasó a representar del 60,5 al $69 \%$ de la población del país; en gran medida el crecimiento poblacional urbano fue debido al proceso de concentración de la población rural que se movió a las localidades urbanas; esto se evidenció en el peso que representala población rural dispersa que pasó del 19,4 al 9,8\%, de 1970 a 1981. 
Un aspecto muy interesante en todo este proceso de concentración y urbanización, lo constituye La Habana, que en el período intercensal mencionado creció a un ritmo lento del $0,7 \%$, mientras las otras ciudades del país, en su conjunto crecieron con un ritmo de $2,3 \%$; en las localidades más pequeñas, como los pueblos y poblados urbanos, el ritmo de crecimiento de la población urbana fue del 3,1 y $3,7 \%$, respectivamente.

En 1981, la población urbana representó el $69 \%$ de la población total y ya en el año 1992 la proporción de la población urbana alcanzó el $74 \%$.

Según la definición oficial del Censo de 1981, se considera asentamiento o lugar habitado a la «agrupación de cinco o más viviendas separadas que no disten entre sí más de doscientos metros, debiendo tener un nombre que le identifique, así como ciertos linderos o límites, de manera que constituya una unidad socio-económica diferente de otras vecinas».

El lugar habitado puede ser conocido como ciudad, pueblo, caserío, batey, granja, hacienda, finca, cooperativa, colonia, central azucarero, etc. A partir de aquí se diferencia el lugar habitado urbano del rural, siendo los primeros: a) aquellos núcleos con una población residente de 2.000 habitantes o más, y b) todos los lugares habitados con una población residente entre 500 y 1.999 habitantes, que dispongan de alumbrado público y tres o más características de las cinco que se relacionan a continuación: acueducto, calles pavimentadas, red de alcantarillado, servicio médico asistencial y centro educacional.

Según la magnitud de los lugares habitados, los asentamientos en Cuba (según el Censo de 1981) se clasifican en: metrópoli, ciudades, pueblos, poblados, caseríos, bateyes y población dispersa. En la categoría de metrópoli entraría únicamente La Habana, por reunir más de medio millón de habitantes. En cuanto a las ciudades, se clasifican en tres órdenes: el primero es el de 100.000 a 499.999 habitantes, que incluye ocho ciudades con una población total de 1.423.351 habitantes; el segundo es el de 50.000 a 99.999 habitantes, con siete ciudades que totalizan 531.184 habitantes; el tercer orden va desde 20.000 a 49.999 habitantes, con 26 ciudades. Las principales ciudades del país aparecen reflejadas en la Figura 7.

$$
-259-
$$


En relación al poblamiento rural de las últimas décadas han existido diferentes políticas relacionadas con las Reformas Agrarias y con el propósito de mejorar las condiciones de vida de la población rural y disminuir sus diferencias con la población urbana. Con las Reformas Agrarias comenzó un proceso de concentración de la población rural alrededor de los bateyes de las centrales azucareros y en las nuevas comunidades rurales, principalmente en la década de los sesenta, en todo el país. Además se desarrollaron otras políticas, donde la población urbana marchaba hacia las zonas rurales, como son las Escuelas en el Campo, sin lugar a dudas un elemento interesante en la distribución de la población cubana.

Actualmente, las políticas más importantes están asociados a intensificar el desarrollo de las zonas montañosas del país; el llamado «Plan Turquino» tiene como objetivo fundamental detener el éxodo de la población de las principales zonas montañosas. También las Cooperativas de Producción Agropecuarias han tenido un papel importante en la concentración de la población rural, así como las Nuevas Comunidades construidas por todo el país.

Muy estrechamente relacionados han estado las migraciones internas y la distribución de la población cubana en toda su evolución. Desde el inicio de la colonización hasta el siglo XVIII los movimientos poblacionales fueron desde las zonas costeras hacia el interior del país y en un sentido este-oeste; desde esta temprana época un papel relevante lo tuvo La Habana, con su puerto que fue centro de atracción de todos los movimientos poblacionales.

En el siglo XVIII y hasta mediados del siglo XIX comienzan diferentes movimientos internos que fundamentalmente ocurrieron en el Occidente del país hasta el centro de la Isla, vinculados al cultivo de la caña de azúcar. A partir de la Guerra de los Diez Años (1868-1878), los movimientos de la población vuelven a tener una dirección del este hacia el oeste, agudizándose la desigual distribución de la población entre el occidente y el oriente del país. A finales del siglo XIX, las migraciones cambian nuevamente con la terminación de la guerra y se produce un «relativo vacío poblacional» en el occidente.

En los inicios de este siglo se produce un crecimiento poblacional en las provincias orientales que se vincula a la gran ampliación del

$$
-260-
$$


cultivo de la caña de azúcar, también se construye la Carretera Central lo que concentra la población a lo largo de este eje longitudinal y provoca un movimiento poblacional desde las zonas más periféricas hacia el mismo.

Después de la crisis de la década del treinta, se produce un fuerte proceso de concentración de la población en las ciudades provocado por los movimientos de los habitantes del campo hacia las mismas. Ocurren importantes movimientos poblacionales entre las provincias limitrofes y en el Censo de 1953, se destaca el papel como provincias receptoras de migrantes que tienen La Habana y Camagüey, la primera por ser la capital y el centro de la actividad económica, política y cultural y Camagüey porque se queda con gran parte de los inmigrantes que iban hacia el este (Morejón, 1976).

A partir de 1959, en los primeros años de la década del sesenta, se produce una nueva corriente inmigratoria hacia el oeste, con nuestas características, ya que estaban formadas por las tropas revolucionarias y sus familias así como campesinos, mujeres y hombres que venían a estudiar como becados a la capital; se produce un importante incremento poblacional en La Habana, debido a estas inmigraciones, llegando a alcanzar un crecimiento del 2,9\% anual en estos años como promedio. En todos estos años con las transformaciones económicas y sociales (leyes de Reforma Agraria, desaparición del desempleo, programas de becas educacionales, etc.) se incrementan las migraciones internas (Junta Central de Planificación, 1966).

Las corrientes migratorias en los últimos treinta años han presentado diferencias importantes desde el punto de vista territorial, las provincias occidentales se han destacado por su carácter receptor, exceptuando la provincia más occidental, Pinar del Río que ha sido tradicionalmente una provincia emisora; las provincias centrales se ha convertido también en provincias receptoras, excepción hecha con Villa Clara que se mantiene como emisora. Todas las provincias orientales son emisoras de población al igual que la Isla de la Juventud, situación que se ha agudizado en los últimos años. El comportamiento de las tasas del saldo migratorio interno para los años 1983 y 1992 aparecen reflejadas en la Figura 8. 


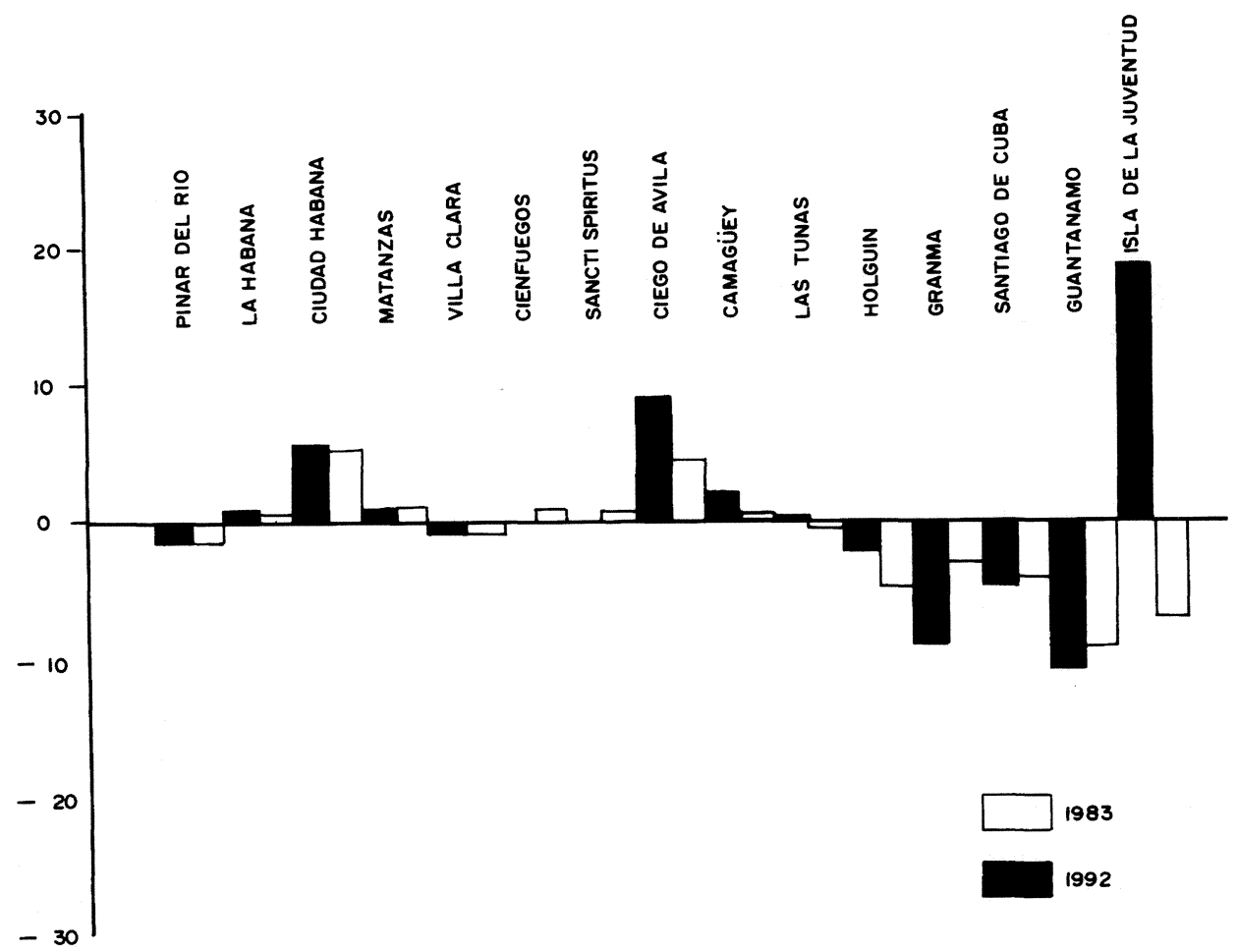

FuENTE: Elaborado por la autora a partir de la información del Anuario Demográfico de Cuba de 1993, CEE.

FIGURA 8.-Tasas del saldo migratorio interno por provincias para Cuba, 1983 y 1992.

En relación a la migración rural-urbana (Montes, 1989), la mayor parte de las emigraciones que ocurrieron en la década de los años setenta procedían de la población dispersa y de los lugares poblados menores de 200 habitantes o por lo general se movían hacia poblados rurales mayores de 200 habitantes (16\%) y hacia las localidades mayores de 2.000 y hasta 20.000 habitantes la restante proporción. Es muy interesante el hecho de que la capital, La Habana, no ejerza su gran poder de atracción para la migración rural como en épocas anteriores y lo demuestra el hecho de que en los últimos diez años ha recibido como promedio sólo 10.000 personas anualmente y la tasa de crecimiento total ha sido alrededor del $1 \%$ y a partir de los años noventa menor de este valor. 
Puede afirmarse que en los últimos años tienen un papel relevante los movimientos de la población cubana a escala local o a pequeñas distancias.

Los diferentes estudios que se han realizado sobre las migraciones internas permiten aseverar que en Cuba predominan los migrantes del sexo femenino que se mueven preferiblemente para las ciudades mayores; otra característica interesante es que la edad de los migrantes, como promedio es de veinte años y que los mismos han tenido un perfil ocupacional vinculado a la esfera de los servicios y administrativa.

\section{Las migraciones internacionales}

Cuando hemos analizado los diferentes componentes de la dinámica de la población cubana, hemos señalado el papel tan importante que han tenido las migraciones internacionales en su formación, por lo que muchas veces se hace referencia a que «Cuba es un país de inmigrantes».

En todo el período colonial existieron diferentes oleadas de inmigrantes; las inmigraciones de esclavos africanos, según Pérez de la Riva, fueron diferentes según períodos; la mayor parte de los mismos arribaron entre 1792 y 1817 con cifras de 281.000 y de 1827 a 1861 , con cifras de 316.000; en total desde 1521 hasta 1873 se estima que llegaron a más de 816.000 esclavos procedentes de África. La inmigración de los «culiés» chinos (Pérez de la Riva, 1966) se calcula en alrededor de 124.000 personas, aunque es probable que haya sido superior esta oleada inmigratoria, que duró desde 1848 hasta 1874 . Como se puede observar tanto el monto demográfico como el período de tiempo es menor que el de las inmigraciones africanas. También entre los años 1849 y 1861 llegaron a Cuba indios yucatecos con un monto estimado alrededor de 2.000 personas.

Las oleadas inmigratorias procedentes de España son, como todos conocemos, las más importantes y por supuesto las más complejas, pero no se pueden apreciar en su monto, ya que todos los habitantes de Cuba eran considerados como españoles. 
Durante las tres primeras décadas del siglo xx llegan a Cuba inmigrantes europeos, básicamente españoles y antillanos que buscaban trabajo y también norteamericanos y chinos. Entre 1902 y 1934 entraron al país más de 1.200 .000 personas, siendo el $56 \%$ procedente de España, el $24 \%$ de las Antillas, el $4 \%$ de Estados Unidos y el $0,4 \%$ de China. Todas estas oleadas migratorias tenían un marcado predominio del sexo masculino y el $80 \%$ de los inmigrantes estaban entre los quince y cuarenta y cinco años.

A partir de los años treinta, las migraciones internacionales prácticamente no tuvieron importancia; muchos españoles regresan a su país, al igual que parte de los antillanos. La migración se invierte y empiezan a emigrar cubanos hacia Estados Unidos, buscando trabajo y tratando de mejorar su situación económica; esto ocurre hasta 1959, donde el triunfo revolucionario conllevó una fuerte oleada inmigratoria.

Con el comienzo de la década de los años sesenta y hasta hoy día, Cuba ha estado marcada por la emigración, que ha variado según sus características en diferentes etapas; en los primeros años de los sesenta, los emigrantes cubanos pertenecían a las clases sociales más altas, posteriormente la emigración ha sido de diferentes clases sociales. Entre 1960 y 1992 han emigrado 844.000 personas, pero entre estos años se destacan las tasas del saldo migratorio externo de 1961, que fue de -10 por 1.000 habitantes y en 1980 que fue de -15 por 1.000 habitantes.

En la década de los años noventa, las emigraciones se mantienen con tasas que oscilan alrededor de -1 por 1.000 . Es interesante destacar que la mayor proporción de emigrantes corresponde entre un 60 y $70 \%$ a la capital; siguiéndola en orden de importancia las provincias de La Habana y Matanzas.

De forma general se puede señalar que la variación de las oleadas emigratorias de Cuba han dependido de la política inmigratoria de Estados Unidos hacia Cuba y su variación ha sido un rasgo característico de la emigración cubana después del triunfo revolucionario, su evolución en los últimos cuarenta años la hemos reflejado en la Figura 9 . 


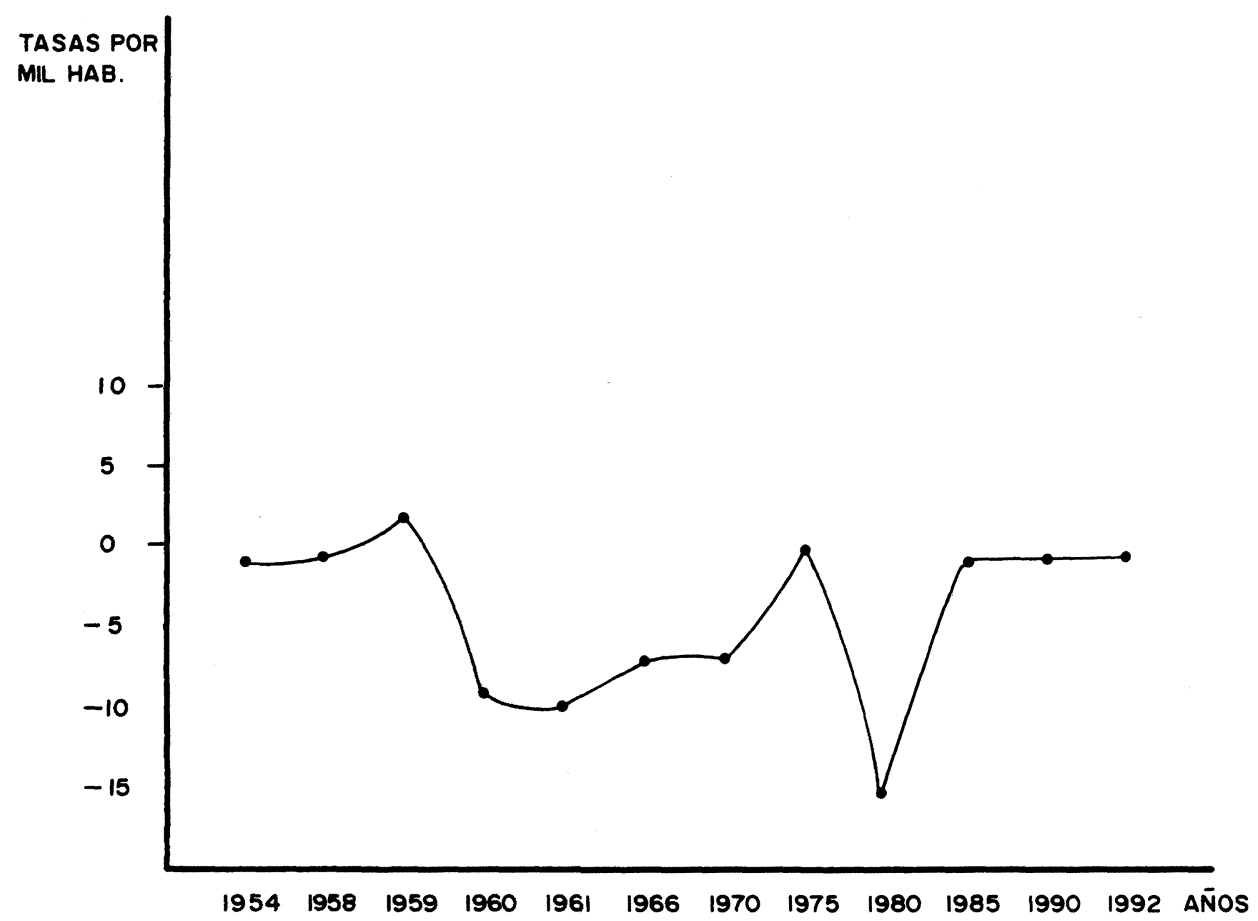

FuENTE: Elaborado por la autora a partir de la información del Anuario Demográfico de Cuba de 1993, CEE.

Figura 9.-Tasas de saldo migratorio externo, 1954-1992.

La población cubana en el siglo XXI

Es bastante interesante y complejo realizar un análisis de la población cubana en un futuro bastante próximo, pero de seguir los indicadores demográficos comportándose con las mismas tendencias de los años noventa, nos podemos atrever, a pesar de la situación del «Periodo Especial» y de la conyuntura internacional, bastante desfavorable para los países menos desarrollados, valorar la situación de Cuba, que, desde el punto de vista poblacional, indiscutiblemente tiene una posición mucho más favorable que la asemeja en sus patrones poblacionales a los países de mayor desarrollo económico y social. 
Con una dinámica problacional, compuesta por valores muy bajos de la natalidad y mortalidad, que hace que las tasas de crecimiento se pronostiquen de $0,13 \%$ para el año 2000 y asciendan hasta $0,37 \%$ en el año 2025 (Naciones Unidas, 1993); de esta forma, la población cubana tendría 11.504 .000 personas en el año 2000 y llegaría a alcanzar 12.993.000 personas en el 2025. La mortalidad general, medida por la esperanza de vida se estima que llegará a alcanzar a principios del siglo próximo los setenta y siete años.

No se pueden hacer suposiciones muy exactas en relación a las migraciones internacionales, ya que ha dependido de diferentes factores coyunturales; es posible que aumenten en los primeros años del próximo siglo.

Por otro lado, el envejecimiento de la población cubana es una realidad que se observa fácilmente en el aumento de las proporciones alcanzadas por la población de sesenta años y más. En el año 2000 se considera que esta población representará el $13,4 \%$ de la población total y en el año 2025 alcanzará la proporción de $22,1 \%$.

Si se cumplen todas estas proyecciones, la población cubana alcanzaría en los primeros años del próximo siglo un nivel estacionario con una estructura de la población envejecida. Otro aspecto de interés es la fuerte concentración de la población en las ciudades y en los pueblos y poblados urbanos y rurales, donde la población rural ha ido concentrándose. El grado de urbanización en la década de los noventa es del $76 \%$ y deberá seguir aumentando, aunque lentamente en los inicios del próximo siglo.

\section{BIBLIOGRAFÍA}

CEE (1994): Anuario Demográfico de Cuba 1993. Instituto de Investigaciones Estadísticas.

CEE (1984): Atlas Demográfico de Cuba. La Habana.

CEE (1984): Censo de población y vivienda, 1981. 16 volúmenes. La Habana.

YDepartamento DE LA GUeRRa (1899): Informe sobre el censo de Cuba, 1899. Apéndice XVIII.

Farnós, A., y Catasús, S. (1976): «La fecundidad», La población de Cuba. Ed. Ciencias Sociales, La Habana, pp. 21-45.

-, y Catasús, S. (1976): «La mortalidad», La población de Cuba. Ed. Ciencias Sociales, La Habana, pp. 47-64. 
- (1992): «Cuba: perspectivas demográficas en el siglo XXI», La demografía cubana ante el $V$ Centenario. CEDEM, Universidad de La Habana, pp. 79-91.

Instituto de Geografía e Instituto de GeOdesia y CARTOGRAFí (1989): Nuevo Atlas Nacional de Cuba. Instituto Geográfico Nacional de España, Madrid.

JUNTA CENTRAL DE PLANIFICACIÓN (1966): Resumen de estadisticas de población, núm. 2. La Habana.

Luzón, J. L. (1987): Economía, población y territorio en Cuba (1899-1983). Ediciones Cultura Hispánica. Instituto de Cooperación Iberoamericana, Madrid, p. 313.

Montes, N., y otros (1989): Tendencias de la concentración y urbanización de la población rural. IPF. JUCEPLAN, p. 42.

Montiel, S. (1988): «Los asentamientos poblacionales en Cuba», Transformaciones del Medio Geográfico en Cuba. Primer Taller Internacional, La Habana, pp. 169-197.

-, y otros (1991): «Los asentamientos poblacionales en Cuba», Eria, 1991, pp. 99-107.

MoreJón, B. (1976): «Distribución de la paisaje y migraciones internas en Cuba», La población de Cuba. Ed. Ciencias Sociales, La Habana, pp. 121-171.

NACIONES UNIDAs (1994): Proyecciones de la población mundial.

Péerez de la RIva, J. (1970): «¿Cuántos africanos fueron traídos a Cuba?», Revista Economía y Desarrollo, núm. 3, p. 141. Publicación Trimestral del Instituto de Economía de La Habana.

- (1966): «Demografía de los culiés chinos en Cuba», Separata de la Revista de la Biblioteca Nacional José Martí, núm. 4, p. 6. La Habana.

- (1972): «Desaparición de la población indígena cubana», Revista Universidad de La Habana, núms. 196-197, 2-3. Impresora Universitaria Andre Voisin.

REPÚBLICA DE CUBA (1994): «Cuba. Informe sobre la evolución de su población y la interrelación con el desarrollo», Conferencia Internacional sobre población y desarrollo. El Cairo, 1994, p. 80.

Rodriguez, O., y HeRnAndez, R. (1976): «El crecimiento de la población», La población de Cuba, Ed. Ciencias Sociales, La Habana, pp. 7-20.

ToIrac, L., y Velázquez, E.: Tablas de mortalidad estimadas por sexos para los años termi nados en cero y cinco, 1900-1950. CEDEM, Universidad de La Habana (inédito). 